OPEN ACCESS

Edited by:

Douglas F Kauffman,

Medical University of the

Americas-Nevis, United States

Reviewed by:

Gerjo Kok

Maastricht University, Netherlands Michael Reiss,

University College London, United Kingdom

*Correspondence:

Loreto Leiva

loretoleivab@u.uchile.cl

Specialty section:

This article was submitted to

Educational Psychology,

a section of the journal

Frontiers in Education

Received: 27 August 2020 Accepted: 13 September 2021

Published: 05 October 2021

Citation:

Torres-Cortés $B$, Leiva $L$, Antivilo-Bruna A and Zavala-Villalón G

(2021) Between Acceptance and

Rejection: How Gender Influences the Implementation Climate of a School

Sexuality Education Program.

Front. Educ. 6:599712.

doi: 10.3389/feduc.2021.599712

\section{Between Acceptance and Rejection: How Gender Influences the Implementation Climate of a School Sexuality Education Program}

\author{
Betzabé Torres-Cortés ${ }^{1,2}$, Loreto Leiva ${ }^{1 *}$, Andrés Antivilo-Bruna ${ }^{2}$ and Gloria Zavala-Villalón \\ ${ }^{1}$ Departamento de Psicología, Universidad de Chile, Nuñoa, Chile, ${ }^{2}$ Centro de Estudios de Intervención e Implementación \\ Psicosocial (CEIP), Santiago, Chile
}

The implementation climate is the shared reception of the individuals involved in the intervention; it is a fundamental determinant of the success of program implementation. One of the factors that affects the implementation climate is gender, since it can influence the commitment of the participants toward sexuality education. This study aims to identify the implementation climate for students who receive a school sexuality education program and explore whether their gender is related to the acceptance of the intervention. A selective quantitative method was used, and a survey was designed to measure implementation climate. A confirmation factorial analysis (CFA) using Mplus 7.0 was conducted to establish the structure of the instrument. A cluster analysis was performed to determine levels of implementation climate. To measure the association between participants' gender and the implementation climate, a Chi-square analysis was performed between each cluster, the gender of the students and each cluster and the type of school (single-sex girls' schools, single-sex boys' schools and co-educational schools). The results demonstrated four levels of implementation climate: acceptance, receptivity, conflict and rejection. Significant differences were observed in the relationship between these levels and the gender of the participants. Acceptance was associated with singlesex girls' schools and female students, conflict and rejection were associated with a singlesex boys' schools and male students, and co-educational schools were associated with conflict. This shows that there is a relationship between the different levels of the implementation climate and the gender.

Keywords: implementation climate, sexuality education program, gender, school, implementation

\section{INTRODUCTION}

Sexuality education has become an area of great interest as a field of study and as a strategy to approach sexual health (Rocha et al., 2016). Sexuality education programs for children and adolescents have become important for the mental health of these groups (Caffe et al., 2017), given the existing vulnerability during that period as a product of teenage pregnancy (Montero, 2011; Silva and Leiva, 2014), risky sexual behavior (Lara and Abdo, 2016) and sexually transmitted infections (STIs; Montero, 2011), among others. Specifically in the Chilean context, adolescent sexuality education is important since the information currently being received is considered insufficient (Obach et al., 2017). 
One of the main places where sexuality education is provided is in schools, which are often considered as the most appropriate place for preventive and promotional initiatives that can foster students' development and allow them to improve their health in a variety of areas (Langford et al., 2014; Weist et al., 2014; Leiva et al., 2015b). Providing sexuality education in school has been demonstrated to be an effective way of preventing STIs and providing information about sexual and reproductive health (Aham-Chiabuotu and Aja, 2017).

There has been increasing interest in the development, implementation and evaluation of successful interventions to promote sexual education (Berglas et al., 2016). This is relevant, since studying the implementation of preventive and promotional programs allows us to recognize the elements that make them effective and develop strategies for their application (Glasgow et al., 1999; Damschroder et al., 2009; Proctor et al., 2009). Implementation research also helps achieve better results (Derzon et al., 2005; Durlak and Weissberg, 2005; Eccles and Mittman, 2006; Durlak and DuPre, 2008; DuPaul, 2009) and quality interventions (Meyers et al., 2012), resulting in more benefits for those who receive the intervention (Durlak and DuPre, 2008), offering empirical evidence of the effectiveness of the programs (Leiva et al., 2015b) and providing relevance to the context in which the intervention takes place (Damschroder et al., 2009; Beidas and Kendall, 2010; Lau et al., 2016).

One of the components used to analyze the execution of programs in implementation research is the implementation climate. This dimension comes from the organizational field (Klein and Sorra, 1996; Weiner et al., 2011); however, there are several approaches to this concept. For this study we used the definition proposed by Damschroder et al. (2009), which through their CFIR model (The Consolidated Framework for Implementation Research), allows the implementation climate to be applied to broader fields than the organizational one, such as health. From the CFIR, this dimension is understood as the shared reception of the individuals involved in the intervention and demonstrates the degree to which the intervention will be rewarded, supported, and received positively (Damschroder et al., 2009; Breimaier et al., 2015). It also indicates the capacity of involved individuals to support and develop changes through the intervention (Hahn et al., 2019).

As it has been identified as one of the determinants of successful interventions in school contexts (Lyon and Bruns, 2019), examining the implementation climate is an important topic (Locke et al., 2016) in understanding the facilitators and barriers of effective implementation (Langley et al., 2010; Weiner et al., 2011) and the development of the relevant components of the internal context of a program (Shuman et al., 2019). A positive climate makes it more probable that a program will be accepted, increasing the possibility of achieving an effective intervention (Turner et al., 2018). This leads to better quality programs that best fit the intended users' values (Weiner et al., 2011), and creates a positive context for putting a program into practice (Ehrhart et al., 2014). In contrast, a poor implementation climate acts as a barrier to obtaining good results (Maritim et al., 2019).

Studying the implementation climate in a school setting focuses on the perception that the school has of the importance of the intervention (Langley et al., 2010), which contributes to its necessity and efficacy problems (Sung et al., 2003). The relevance of the implementation climate for school programs is also key, because it is fundamental for preventative strategies (Fixsen et al., 2005), and includes a contextual element that can be determinant in the capacity of the school community to support a program (Klein and Knight, 2005; Weiner, 2009).

Damschroder et al. (2009), in the Consolidated Framework for Implementation Research, highlight that the implementation of programs has different general domains that can have a positive or negative impact. One of these domains is the internal context, which refers to the characteristics, variables, and structural, political and cultural circumstances of the implemented intervention. The implementation climate is a dimension of the internal context, and can be measured through Tension for Change, Compatibility, Relative Priority, Organizational Incentives and Rewards, Objectives and Feedback, and Climate of Learning (Damschroder et al., 2009). In this study, the implementation climate was evaluated through the subdimensions Tension for Change and Compatibility. Although some studies include all the dimensions and sub-dimensions of the CFIR, others-like this study-include only some of them (Kirk et al., 2015). The decision was made to include Tension for Change and Compatibility because these dimensions allow us to respond to the objective of the research and facilitate the analysis of the implementation of sexuality education programs from a gender perspective.

Tension for Change includes statements that demonstrate a strong need for innovation and that the current situation is untenable. This dimension is critical in a sexuality education program since, if there is a traditional perspective of gender where the intervention will be implemented, the program may not be considered necessary. Compatibility includes personal value elements and how these are similar to those of the intervention (Damschroder et al., 2009). Thus a person with traditional gender values may consider that sexuality education does not fit into his or her value system. Therefore, the inclusion of both sub-dimensions allows us to analyze how gender can influence the implementation of sexuality education programs.

Tension for Change is a key factor in determining the success of putting an intervention into practice and its subsequent results (Liang et al., 2015; Breland et al., 2016). It refers to the extent to which the involved individuals believe that their current situation is intolerable or merits change (Damschroder et al., 2009). It also relates to the need for intervention; that is, the best time to implement a practice is when it is most needed (Liang et al., 2015). Compatibility is the degree of tangible adjustment between the significance and values associated with the intervention and the individuals involved, and how they align with the proper norms, values, risks and perceived necessity, as well as the manner in which the intervention can adjust to the existing norms (Greenhalgh et al., 2004). Thus the more that people perceive the meaning that they give to the program as aligned with their values, the stronger the results of the implementation (Damschroder et al., 2009), and the more likely it is that the intervention will be adopted (Greenhalgh et al., 2004). Consequently, when the values of the individuals involved are 
understood, it is easier to create an alliance to achieve a faster adoption process (Denis et al., 2002), and the most successful teams are those that adapt to the value system of the community (Varsi et al., 2015).

The evidence suggests that the main factors that affect the implementation climate are socio-cultural norms, socioeconomic status, type of leadership and the degree of literacy (Aarons et al., 2014). A study by Ninsiima et al. (2019) points out that one of the factors that affects acceptance of an intervention is gender. Gender can be key due to its impact on program implementation (Tannenbaum et al., 2016). Gender can be understood as the socially constructed roles, behaviors, activities and attributes that society considers appropriate for males, females and other genders (Morgan et al., 2016). This social construction of roles, identities and behaviors influences how people perceive themselves and others, their interactions and the distribution of power and resources in society (Heidari et al., 2016); it generally organizes and regulates the values associated with gender among institutions (Johnson et al., 2009) and intersects with other social categories such as sex, age, and ethnicity (Gendered innovations, 2020).

Gender has various components, such as gender roles, identities, and relations (Tannenbaum et al., 2016). Gender roles are behavioral norms socially applied to men, women, and other genders, being more similar in some cultures than others (Johnson et al., 2009). Gender identity is how individuals and groups perceive and present themselves and how they are perceived by others (Gendered Innovations, 2020). Gender relations incorporate how people interact based on the experienced or attributed gender, and in most cultures reflect differential power between women and men and often disadvantage women (Johnson et al., 2009).

Implementation has a social nature, and thus gender has substantial effects on the different stages of the program through the dynamics of gender (Tannenbaum et al., 2016); it also plays a central role in the assimilation and practice of interventions (Pawson, 2013), gender stereotypes (Brown and Stone, 2016) and power relations (Kululanga et al., 2011). Thus gender is one of the elements that can influence the implementation climate of an intervention, since it could affect interpersonal communication (Olson et al., 2020) and change the participants' commitment towards sexuality education (Ninsiima et al., 2019).

In Latin American cultures such as Chile, sexuality education has been characterized by biological reductionism and heteronormativity (Macintyre et al., 2015; Obach et al., 2017). Historically, sexual and reproductive health has been related to women (Sadler et al., 2010), contrary to what has happened to teenage men who are not actively included in sexual and reproductive health services (Obach et al., 2018). Indeed, the idea persists that sexuality is a particular issue for women and not something that men need to have knowledge about (Sadler et al., 2010). These cultural elements of gender in sexuality education could also affect how students receive such an intervention. Thus, given that gender can affect the implementation of the intervention as well as how people assimilate and commit to it, the present study aims to identify the implementation climate of a school sexuality program and explore whether the gender of those who receive the intervention (students) is related to this climate.

The innovative aspect of this study is based on Implementation Science. This is the scientific study of the processes and components of implementing evidence-based interventions in everyday implementation settings (Eccles and Mitman, 2006). Gender is not usually included as a central element of the analysis in implementation studies (Tannenbaum et al., 2016), but is a current practice in health research (Greaves, 2012). None of the most popular texts on implementation research have chapters dedicated to the effect of gender on the implementation of programs, while only a few articles mention this concept. Gender has also not been given importance in implementation theories (Tannenbaum et al., 2016). Therefore, incorporating a gender approach in implementation studies is an innovative theoretical aspect. Although there are studies on the gender of participants in sexuality education programs, such as that of Measor (1996), gender has not been sufficiently included in Implementation Science.

The methodology of this study implies an empirical measurement of the implementation climate, which is scarce in the field of mental health (Weiner et al., 2011), specifically in the school context (Lyon et al., 2018), the area where this study was carried out. This measurement was associated with the development of a specific survey for a school sexuality program. This study also reduces the breach between what is known about this type of intervention and what is carried out (Fixsen et al., 2005; Wandersman et al., 2008) to understand how gender affects the way a sexuality education program is received, filling the research gap that exists in this area. In this way, sexuality education programs can adapt to the local context of the school and the implementation of these programs can be improved and oriented towards the culture and climate of the school (Forman et al., 2013) in such a way that the intervention will be sensitive to gender differences. This augments the production of information on implementation strategies to support the work of those professionals who intervene in the school context (Forman et al., 2013). Finally, it is worth mentioning that according to the background search, there are few studies on the role of gender in the implementation climate of sexuality education programs.

\section{MATERIALS AND METHODS}

A selective quantitative method was used for this study, and a survey was designed that included a record of the students' opinions using a scale of answers (Ato et al., 2013), which allowed for a classification of types (Neuman, 2013). This study was conducted with PROCES (County Sexuality Education Program; Programa Comunal de Educación Sexual, in Spanish), developed by the Department of Education of the city of Santiago, Chile. PROCES is a school-based sexuality education program aimed at students from public schools in Santiago. Most 
of these students come from low-income families. The program is carried out in all 44 schools in the district.

PROCES aims to train students to have a healthy sexual life. It addresses the affective, spiritual, ethical, and social dimension of healthy sexual development with respect for human life, diversity and dignity. The intervention includes promotional and preventive strategies, targeting factors such as 1) interpersonal relationships, 2) characteristics of sexual health, 3) self-care and lifestyles, and 4) training in politics and inclusive language (Department of Education of the Municipality of Santiago, 2018). All schools in Santiago are required to implement PROCES. The program provides guidelines on objectives and topics for each age group and requests schools to incorporate the Gender Approach.

\section{Participants}

The total number of participants was 1,412 students, from 8 schools in Santiago, Chile. Three of these were co-educational high schools, two single-sex boys' high schools and three single-sex girls' schools. Professional school administrators involved in the decision-making related to the program were included. These included directors, counselors, psychologists, school life managers and school integration coordinators. The students included in the study were in seventh to tenth grade (between 12 and 16 years old) and had participated in the first year of the program implementation. They were chosen for their age and because they are in a sensitive period with respect to the issues addressed by the intervention (López et al., 2017).

Of all surveys answered $(1,412)$, students who did not sign the informed settlement $(n=29)$ and students younger than 12 or older than $16(n=41)$ were not included. Atypical responses ( $n=39$; showing that the participant did not respond thoughtfully to the survey) and those who did not respond to all of the questions $(n=144)$ were also discarded, resulting in a final sample of 1,159 students. Thus in the final sample $51 \%$ ( $n=588$ ) were female students, $84 \%$ of the students had Chilean nationality $(n=971), 34 \%(n=396)$ were in the seventh and eighth grades, $23 \%(n=267)$ were in the ninth grade, and $43 \%$ $(n=496)$ were in the tenth grade.

\section{Instrument}

An instrument was created to identify the existing implementation climate. To construct the instrument, the existing literature was reviewed (Creswell, 2012), and the model used by Damschroder et al. (2009) was adopted, which measures "Tension for Change" and "Compatibility". It is worth mentioning that no previous model was used to create the instrument.

Tension for Change was measured through two subdimensions: 1) "Changes," defined as the degree to which a situation is perceived as intolerable, or that requires change, and 2) "Necessity," understood as the interest in putting the intervention into practice. Compatibility was measured through the dimension "Values," implying the level of adjustment between the values of the program and of the students. Specific questions related to gender were incorporated in the Values sub-dimension; for example, "My ideas and values on gender resemble those presented by PROCES."
The survey statements were created using a 10-point Likert scale (Creswell, 2012) that varied between "Totally disagree" and "Totally agree." These were reviewed by the authors and program managers of the participating schools. Program managers were psychologists, counselors, or social workers, and from their feedback, for questions with less than $70 \%$ agreement the wording was modified to improve comprehension. A pilot survey of 78 students with similar characteristics to those of this study's population was carried out, adjusting the number of options in some questions and simplifying the wording to facilitate reading and understanding. This survey was made up of 26 questions (Table 1).

\section{Data Analysis}

A confirmation factorial analysis (CFA) using Mplus 7.0 was conducted with the sample of students to establish the structure of the instrument. A cluster analysis was conducted using IBM SPSS 25.0 to establish the current levels of implementation climate.

After identifying the clusters, Chi-square tests were carried out to establish the relationship between students' gender, type of school (single-sex girls', single-sex boys' and co-educational schools), and levels of implementation climate. IBM SPSS 25.0 was used.

It is worth mentioning that the concept of gender fluidity (non-binary) was used. When students were asked about their gender, some identified with the option "Other." $(n=15)$

\section{RESULTS}

\section{Factorial Structure of the Implementation Climate Survey}

Given that the instrument had a theoretical base, it was verified that the questions were related to the underlying latent factors (Byrne, 2010). The adjustment of three theoretical models was evaluated through the CFA, using the proposals by Damschroder et al. (2009) to measure the Tension for Change and Compatibility.

The adjustment of each model was estimated using four indicators: Chi-squared analysis $\left(\chi^{2}\right)$ and its rate with degrees of liberty $(\chi 2 / \mathrm{gl})$, Root Mean Square Error of Approximation (RMSEA), Confirmatory Fit Index (CFI), and the Tucker-Lewis Index (TLI). These should all comply with the stipulated conditions for this type of analysis (Browne and Cudeck, 1992), and weights of 0.30 were considered to interpret the weight of each factor, (Hair et al., 1999).

First, models with one and two factors were examined (Tension for Change and Compatibility) that did not reach a degree of adjustment (Table 2). Then a model that included a general factor (Tension for Change) and two sub-factors (Necessity and Changes) were contrasted. A bifactor analysis was conducted (Patrick et al., 2007; Gibbons et al., 2009; Sheldrick et al., 2012) in which the questions about Tension for Change (17 in total) were weighed as a general factor, but at the same time weighed in two other factors: Changes (7 questions) and Necessity (10 questions). 
TABLE 1 | Factor loads of each item by bifactor model dimension for the Implementation Climate survey.

\begin{tabular}{|c|c|c|c|c|}
\hline $\begin{array}{l}\text { Item } \\
\text { number }\end{array}$ & Statement & Dimension & Bifactor & $\begin{array}{l}\text { General } \\
\text { factor }^{a}\end{array}$ \\
\hline 1 & Do you believe that your school needs help to teach topics like sexuality & $\mathrm{CHA}$ & 0.72 & 0.19 \\
\hline 2 & Do you believe that your school needs help to teach equality between men and women & $\mathrm{CHA}$ & 0.63 & 0.49 \\
\hline 3 & Do you think your school requires help for sex education in terms of diversity, discrimination, etc. & $\mathrm{CHA}$ & 0.73 & 0.39 \\
\hline 4 & $\begin{array}{l}\text { Do you think that your school needs a program that deals with sex education (a program run by your own } \\
\text { school or carried out by others from outside your school) }\end{array}$ & $\mathrm{CHA}$ & 0.81 & 0.10 \\
\hline 5 & $\begin{array}{l}\text { Do you think your school requires a program that deals with the issue of equality between men and women (a } \\
\text { program run by your own school or carried out by others from outside your school) }\end{array}$ & $\mathrm{CHA}$ & 0.83 & 0.27 \\
\hline 6 & $\begin{array}{l}\text { Do you think your school needs a change the way it carries out sex education (whether it be in classes or other } \\
\text { activities) }\end{array}$ & $\mathrm{CHA}$ & 0.73 & 0.27 \\
\hline 7 & $\begin{array}{l}\text { Do you think your school needs to change the way it teaches equality between men and women (whether it be } \\
\text { in classes or other activities) }\end{array}$ & $\mathrm{CHA}$ & 0.66 & 0.48 \\
\hline 8 & Do you believe that PROCES is needed to deal with the topic of sexuality in your school & NEC & 0.77 & 0.01 \\
\hline 9 & Do you believe that PROCES is needed to teach equality between men and women & NEC & 0.80 & 0.14 \\
\hline 10 & Do you think your school is prepared to receive PROCES & NEC & 0.63 & -0.46 \\
\hline 11 & Do you think your school needs to receive PROCES & NEC & 0.64 & -0.40 \\
\hline 12 & Do you think that the students want PROCES to be realized at your school & NEC & 0.80 & -0.22 \\
\hline 13 & Do you think that PROCES is helpful for what your school needs to learn about sexuality & NEC & 0.88 & -0.04 \\
\hline 14 & Do you think that PROCES is helpful for what you need to learn about sexuality & NEC & 0.84 & 0.01 \\
\hline 15 & $\begin{array}{l}\text { Do you think that PROCES is helpful for what your school needs to learn about equality between men and } \\
\text { women, sexual discrimination, sexual diversity, etc. }\end{array}$ & NEC & 0.87 & 0.11 \\
\hline 16 & $\begin{array}{l}\text { Do you think PROCES is helpful for what you need to learn about equality between men and women, sexual } \\
\text { discrimination, sexual diversity, etc. }\end{array}$ & NEC & 0.80 & 0.13 \\
\hline 17 & Do you think that PROCES is necessary for your school & NEC & 0.86 & 0.04 \\
\hline 21 & Do you think that PROCES approaches topics that are important for students & COMP & 0.92 & \\
\hline 22 & Do you think that PROCES approaches topics that are important for your school & COMP & 0.93 & \\
\hline 25 & Do you think your ideas and values about sexuality are similar to those taught by PROCES & COMP & 0.70 & \\
\hline 26 & $\begin{array}{l}\text { Do you think your ideas and values about equality between men and women, sexual discrimination, and sexual } \\
\text { diversity are similar to those taught by PROCES }\end{array}$ & COMP & 0.73 & \\
\hline
\end{tabular}

Note: $\mathrm{CHA}=$ Changes; $\mathrm{NEC}=$ Necessity; $C O M P=$ Compatibility .

${ }^{a}$ Tension for Change.

TABLE 2 | Models adjustment indicators.

\begin{tabular}{lcccccc}
\hline Model & $\chi \mathbf{2}$ & $\chi \mathbf{2} / \mathbf{g l}$ & $\boldsymbol{p}\left(\chi^{2}\right)$ & $\begin{array}{c}\text { RMSEA (IC } \\
\mathbf{9 0 \% )}\end{array}$ & CFI & TLI \\
\hline 1 Factor & 7409.24 & 230 & 0 & $0.264(0.161-0.168)$ & 0.727 & 0.700 \\
2 Factors & 6372.8 & 229 & 0 & $0.152(0.149-0.156)$ & 0.766 & 0.742 \\
Bifactor & 1253.69 & 169 & 0 & $0.075(0.071-0.078)$ & 0.958 & 0.948
\end{tabular}

The bifactor model tested (Figure 1) was adequate and demonstrated a result that was theoretically and statistically interpretable. There was also satisfactory reliability ( $\alpha$ ordinal= 0.96). Each factor reached an adequate level of reliability (Prieto and Delgado 2010): Change, $\alpha$ ordinal $=0.88$, Necessity, $\alpha$ ordinal $=0.94$, and Compatibility, $\alpha$ ordinal $=0.89$. The Alpha Ordinal was calculated to estimate the evidence of reliability through internal consistency, which is commonly used in response categories (Domínguez Lara, 2012).

\section{Identification of the Levels of Implementation Climate}

A cluster analysis was conducted on the surveys to classify the levels of implementation climate. A non-hierarchical method was used, as the cluster number was already determined $a$ priori (Pastor, 2010). The cases were grouped according to the level of the score of the variables-Tension for Change and Compatibility-and in turn, the pattern was in conjunction with the scores (DiStefano and Kamphaus, 2006). The initializing method used was Quick Cluster. Then each individual was assigned to the cluster with the nearest centroid through the $\mathrm{k}$ means algorithm, and the centroid of the cluster was recalculated after all of the cases were assigned in each interaction.

The cases were grouped in four initial clusters. In the iterations, the change of the maximum absolute coordinates for any center was 0.000 ; the iteration was 16 and the minimum distance between the initial centers was 53.141. The grouping presented in Table 3 was obtained by recalculating the centroid of the cluster. A difference in the homogeneity of the groups was observed between the distinct group Tension for Change $(\mathrm{F}(0.000)=4148.2 ; p<0.05)$ and compatibility $(\mathrm{F}(0.000)$ $=15280.31 ; p<0.05)$.

The completed four clusters of implementation climate of the analysis were identified as follows:

1) Acceptance: made up of a high level of Tension for Change and Compatibility in $32 \%$ of the students. This is defined as a high necessity of the program and compatibility with its values 


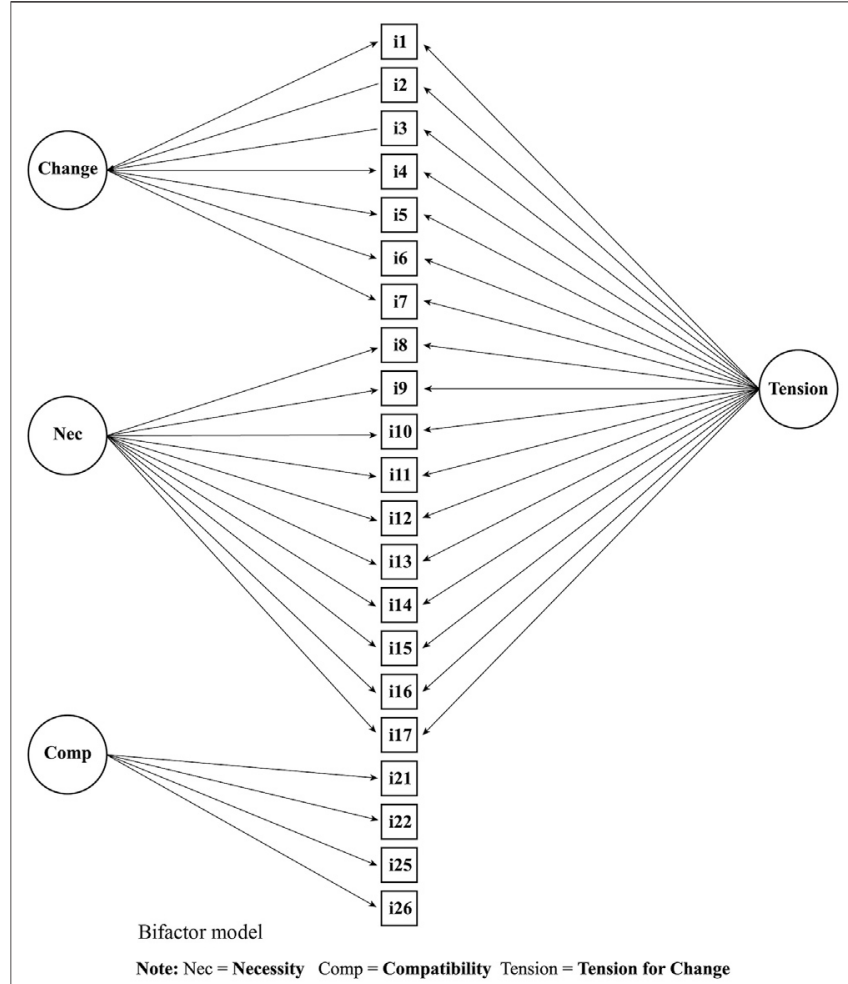

FIGURE 1 | Bifactor model of the Implementation Climate survey.

and meanings. There is high positive receptivity to PROCES, which is both received positively and supported.

2) Receptivity: made up of a medium level of Tension for Change and Compatibility, in $31 \%$ of the students. This refers to a medium level of necessity of the program and certain compatibility with its values and meanings. There is a good reception to PROCES; however, it is possible that there is not complete support.

3) Conflict: made up of a medium-low level of Tension for Change and Compatibility in $29.2 \%$ of the students. This is defined as a medium-low level of necessity for the program and compatibility with its values and meanings. There is scarce necessity for the program and low compatibility with its values and meanings.

4) Rejection: made up of a low level of Tension for Change and Compatibility in $8 \%$ of the students. The intervention is not expected as there is a perception that it is not necessary for the school and is not compatible.

These are illustrated in Figure 2.

\section{Gender and Implementation Climate}

A statistically significant association was found in the relationship between each cluster and the gender of students $\left(\mathrm{x}^{2}{ }_{(6)}=54.72\right.$; $p<0.001)$. The results show that despite the distribution of students of different genders at all levels of the implementation climate, acceptance was associated with female students and conflict and rejection with male students (Table 4).
A significant relationship was found between each group and the type of school (single sex or co-educational) $\left(\mathrm{x} 2{ }_{(9)}=72.7\right.$; $p<0.001)$. Acceptance was associated with single-sex girls' schools, conflict with co-educational schools, and rejection with single-sex boys' schools (Table 4).

\section{DISCUSSION}

This study aimed to determine the types of implementation climate that can be developed in schools for sexuality education programs and to understand how students' gender can influence the implementation climate. The results identified four levels of implementation climate from the intervention, which would require different coping strategies to promote the adoption of the intervention and decrease the level of resistance towards the program (Beidas and Kendall, 2010; Lau et al., 2016). Acceptance was the largest percentage (32\%), and with receptivity made up $63 \%$ of cases, from which it can be inferred that the students had an implementation climate with adequate receptivity to the program. This is relevant, as positive reception to sexuality education programs creates a context that is beneficial to the progress of the program (Ehrhart et al., 2014).

These results are encouraging with respect to the development of a sexuality education program, as the implementation climate is a reflection of the context in which it is carried out. This has an impact on the success of the intervention and improves the likelihood of adoption and maintenance of the results (Beidas and Kendall, 2010; Lau et al., 2016). Although the intervention is in its initial stages of implementation, its receptivity is positive; as it continues being carried out in schools this should grow, and if the program is accepted, it is more likely to be effective (Turner et al., 2018).

Significant differences were observed in the relationship between gender and types of implementation climate identified. Acceptance was related to single-sex girls' schools and female students. Conflict and rejection were related to single-sex boys' schools and male students. In co-educational schools, which were associated with conflict on the individual level, girls tended to accept sexuality education while boys tended to reject it. These differences show that gender is a factor that could influence individual response to the program (Allen et al., 2012); this indicates that the implementation climate is not independent of the student's gender.

An implementation climate of conflict and rejection toward a sexuality program in boys' schools and from

TABLE 3 | Implementation climate clusters.

\begin{tabular}{lccccccc}
\hline & \multicolumn{3}{c}{ Tension for change } & & \multicolumn{3}{c}{ Compatibility } \\
\cline { 2 - 5 } \cline { 6 - 8 } & N & M & SD & & N & M & SD \\
\hline Acceptance & 368 & 168 & 12 & & 368 & 35 & 5.13 \\
Receptivity & 357 & 135 & 12 & & 357 & 29 & 6.3 \\
Conflict & 337 & 102 & 12 & & 337 & 22.2 & 6.4 \\
Rejection & 92 & 60 & 16 & & 92 & 13.45 & 8
\end{tabular}




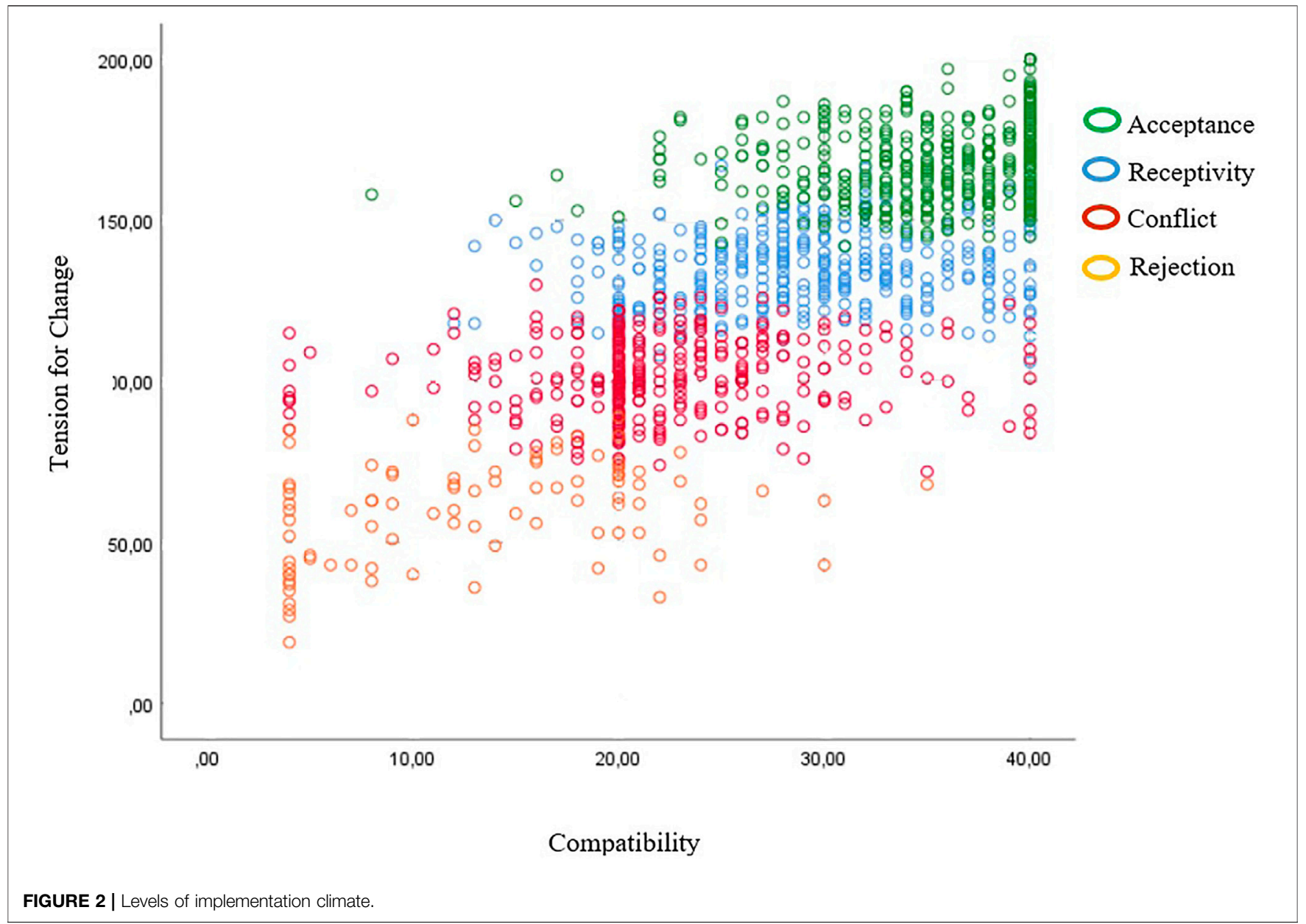

TABLE 4 | Association between implementation climate and participants'gender and type of school.

\section{Gender}

Masculine
Femenine
Other
Total
Type of school
Single-sex Boys' High School
Coeducational Schools
Single-sex Girls' School
Total

male students could be understood in the context of heteronormativity and biological reductionism of sexual education in Chile (Macintyre et al., 2015; Obach et al., 2017). The relationship between acceptance, girls' schools and female students could be understood because sexual and reproductive health in Chile has historically been linked with women and excluded men (Sadler et al., 2010; Obach et al., 2017). Such behaviors can be observed not only 
in Latin America but also in countries such as the United Kingdom, Australia, Norway, and New Zealand (Macintyre et al., 2015).

This shows the relationship between the implementation climate, culture and gender, because gender interacts with other social categories (Johnson et al., 2012). The sociocultural system also influences how people experience their gender, thus the context contributes to whether gender is perceived more traditionally or flexibly. The more traditional way may lead to a greater rejection of the sexuality education program, while the more flexible way may help to accept it more easily. Sociocultural factors associated with gender may be a barrier in the implementation of this type of intervention (Ninsiima et al., 2019), which may determine students' reception to the intervention. As a result, heteronormativity in sexuality education can promote gender inequalities in students (Tarkang, 2014), distortion in the understanding of sexual orientation, discrimination against peers with different sexual orientations (Macintyre et al., 2015), and stereotype emergence (Johnson et al., 2009; CIHR, 2012).

This situation is observed in the different school implementation climates in the program studied. From interviews conducted with teachers and program managers, information was obtained that although teachers carry out the program activities in most schools, the implementation of the program is different in each. For example, some schools (mostly single-sex boys' schools) focus on the biological aspects of sexuality, have a heteronormative view of sexuality and include only heterosexual content; while others (mostly singlesex girls 'schools) include content on affectivity, use a gender and inclusion approach and have content on sexual diversity. This context influences how students perceive their gender and sexuality, as more traditional schools may lead them to reject the intervention, while more flexible schools may promote their acceptance.

The results confirm the importance of gender in the implementation of programs and demonstrate how differences in gender can influence the acceptance of sexuality education (Ninsiima et al., 2019). Although the program may establish guidelines that promote gender focus, the cultural aspects associated with gender could hinder its smooth implementation. This makes it necessary to take steps to address these elements either before or during the implementation of the program. The aforementioned is key in comprehensive sexuality education programs, which in addition to having a human rights and gender equity perspective, involve various dimensions of sexuality, such as abstinence, pregnancy prevention, STD/HIV, sexual diversity and partner violence, among others (Kirby, 2006; Rotheram-Borus et al., 2008; Haberland, 2015; Wang et al., 2015; Panchaud et al., 2018; UNESCO, 2018).

Given that these types of programs promote gender norms associated with more flexible sexuality and a decrease in gender stereotypes, they have a higher probability of being rejected when there is an implementation climate with a traditional gender approach. Therefore, the gender norms and values associated with sexuality in the school should be evaluated before implementing a comprehensive program. If the norms and values are more traditional, it will be necessary to carry out actions before implementing the intervention to strengthen the gender approach in the educational community to ensure a better implementation climate for the program.

This study provided relevant information about gender influence in the implementation climate of a sexuality education program, which has implications for the Chilean and Latin American contexts. It is necessary to point out that although sexuality education programs in Latin America have similarities, there are also differences based on the cultural context (Estrada et al., 2021). The results assist in understanding the reality of the implementation of sexuality education school interventions, and based on this knowledge can help to identify which elements would help to strengthen these programs. This is crucial because, there is little evidence in this regard in many low and middle-income countries (Keogh et al., 2020). In addition, the scope of this type of education in schools is limited in the Latin American educational field, (Demaria et al., 2009).

Finally, the implementation climate adopts a critical role as it reflects whether or not a school is open to the intervention or considers that it does not respond to its needs or systems, reflections that can facilitate or hinder implementation of an intervention (Maritim et al., 2019). The present study highlights the role of gender in the formation of the implementation climate of a school sexuality program. This is especially sensitive in the school environment, as parallel to other social institutions, schools can transmit gender stereotypes that can influence students' attitudes (Chanzanagh et al., 2011). It could be hypothesized that there is a collective influence of gender in this study. There was greater resistance in the single-sex boys' schools, while there was more openness in the single-sex girls' schools. This can be explained by institutionalized gender (Johnson et al., 2009; Tannenbaum et al., 2016), because the school's system of beliefs and values around gender affect its attitude toward sexuality.

From this perspective, each educational community would develop an institutionalized gender. If the school is associated with more traditional values in terms of sexuality and gender relations, it is more likely to have a rejection or conflict type of climate. In the single-sex boys' schools, the institutionalized gender would organize the values associated with sexual education from a more traditional or hegemonic perspective.

Future research could address the hypotheses raised and assess whether there is an institutionalized gender in schools which would be influencing the implementation climate.

\section{Limitations}

One of the limitations of the present study is the limited number of students who identified with the "other" gender alternative, which makes it difficult to generalize the results and reduces the inclusion of their perspective. Consequently, the results must take cultural differences in the implementation of sexuality education 
programs into consideration. In addition, the limited number of schools may make it difficult to generalize the results.

\section{Suggestions for Future Research}

According to the results, a key recommendation is the necessity to develop practices that are gender-responsive at the initial stages of the implementation of sexuality education programs. These strategies are necessary to address institutionalized gender and the gender role of the students to create an implementation climate that contributes to the effectiveness of the intervention. Evaluating the implementation climate as the starting point of the process of developing a program is essential, as it will determine the perspective of the educational community and identify ways to adjust and respond to the school's needs, values, interests and ways of working. This allows the program to meet the goals pursued by the intervention. For this, it is necessary to collect information by gender (Alexander and Walker, 2015), identifying differences in beliefs and practices which are influencing the perspective of involved individuals (students, teachers, administrators, among others) towards the program. This provides basic knowledge that allows deciding how to incorporate gender considerations (Caro et al., 2009). Based on this information, activities that address these gender differences in the implementation climate can be designed.

Future research must examine gender in the implementation climate, and analyze how the gender role of students and institutionalized gender of the school create different types of receptivity to sexuality education program. Likewise, it would be relevant to study the incidence of gender in the receptivity of interventions in various contexts, such as rural and urban schools, migrant or ethnic students, and schools in different territorial areas of the country, among others.

In conclusion, this study highlights the input of the studies on the implementation of design, transference, and maintenance of sexuality education programs. The results have provided a more holistic picture of these programs, improved their quality and effects, and connected research and the application of evidence (Eccles and Mittman, 2006; Durlak and DuPre, 2008; Meyers et al., 2012; Leiva et al., 2015a). In addition, they generate knowledge that can be applied to develop gender-sensitive sexuality programs, considering how they affect the acceptance or rejection of such interventions.

\section{REFERENCES}

Aarons, G. A., Ehrhart, M. G., Farahnak, L. R., and Sklar, M. (2014). Aligning Leadership across Systems and Organizations to Develop a Strategic Climate for Evidence-Based Practice Implementation. Annu. Rev. Public Health. 35, 255-274. doi:10.1146/annurev-publhealth-032013-182447

Aham-Chiabuotu, C. B., and Aja, G. N. (2017). "There Is No Moral They Can Teach Us": Adolescents' Perspectives on School-Based Sexuality Education in a Semiurban, Southwestern District in Nigeria. Am. J. Sex. Educ. 12, 315-336. doi:10.1080/15546128.2017.1280442

Alexander, S., and Walker, E. M. (2015). Gender-based Health Interventions in the United States: An Overview of the Coalition for Healthier Community Initiative. Eval. Program Plann. 51, 1-3. doi:10.1016/ j.evalprogplan.2015.02.004

Allen, J. D., Linnan, L. A., and Emmons, K. M. (2012). "Fidelity and its Relationship to Implementation Effectiveness, Adaptation, and Dissemination," in Dissemination and Implementation Research in Health: Translating Science to Practice. Educ. Rev.

\section{DATA AVAILABILITY STATEMENT}

Data generated during the current study are available from the corresponding author on reasonable request.

\section{ETHICS STATEMENT}

The authors received institutional authorization from the Municipality of Santiago to conduct the study. Participation was voluntary and confidential, and received authorization from the Ethics Committee of the Universidad de.

\section{AUTHOR CONTRIBUTIONS}

BT-C. Conceived the presented idea, developed the survey and performed the measurements. AA-B. Conceived the presented idea, performed the measurements and oriented and verified the analytical methods. GZ-V. Supervised the introduction and discussion sections. LL Conceived the presented idea, encouraged BT-C to investigate the Implementation Science and supervised the findings of this study as the principal investigator, and contributed to the writing and editing of the article. All authors discussed the results and contributed to the final article.

\section{FUNDING}

This study was supported by the National Scientific and Technological Development Fund under the Grant Fondecyt Regular Project No. 1171634.

\section{ACKNOWLEDGMENTS}

We thank the Department of Education of the city of Santiago, Chile for supporting this research.

Editors R. C. Brownson, E. K. Proctor, and G. A Colditz (New York, NY: Oxford), 281-304. doi:10.1093/acprof:oso/9780199751877.003.0014

Ato, M., López-García, J. J., and Benavente, A. (2013). Un sistema de clasificación de los diseños de investigación en psicología. analesps 29, 1038-1059. doi:10.6018/analesps.29.3.178511

Beidas, R. S., and Kendall, P. C. (2010). Training Therapists in EvidenceBased Practice: A Critical Review of Studies from a Systems-Contextual Perspective. Clin. Psychol. (N.Y) 17, 1-30. doi:10.1111/j.14682850.2009.01187.x

Berglas, N. F., Jerman, P., Rohrbach, L. A., Angulo-Olaiz, F., Chou, C.-P., and Constantine, N. A. (2016). An Implementation and Outcome Evaluation of a Multicomponent Sexuality Education Programme for High School Students. Sex Educ. 16, 549-567. doi:10.1080/14681811.2015.1133408

Breimaier, H. E., Heckemann, B., Halfens, R. J., and Lohrmann, C. (2015). The Consolidated Framework for Implementation Research (CFIR): A Useful Theoretical Framework for Guiding and Evaluating a Guideline Implementation Process in a Hospital-Based Nursing Practice. BMC Nurs. 14, 43. doi:10.1186/s12912-015-0088-4 
Breland, J. Y., Asch, S. M., Slightam, C., Wong, A., and Zulman, D. M. (2016). Key Ingredients for Implementing Intensive Outpatient Programs within PatientCentered Medical Homes: A Literature Review and Qualitative Analysis. Healthc (Amst) 4, 22-29. doi:10.1016/j.hjdsi.2015.12.005

Brown, C. S., and Stone, E. A. (2016). "Gender Stereotypes and Discrimination," in Gender Stereotypes and Discrimination: How Sexism Impacts Development in Equity and justice in Developmental Science: Theoretical and Methodological Issues. Editors S. Horn, M. Ruck, and L. Liben (Cambridge, MA: Elsevier Ltd), 105-133. doi:10.1016/bs.acdb.2015.11.001

Browne, M. W., and Cudeck, R. (1992). Alternative Ways of Assessing Model Fit. Sociological Methods Res. 21, 230-258. doi:10.1177/0049124192021002005

Byrne, B. M. (2010). Structural Equation Modeling with AMOS: Basic Concepts, Applications, and Programming (Multivariate Applications Series). New York: Taylor \& Francis Group.

Caffe, S., Plesons, M., Camacho, A. V., Brumana, L., Abdool, S. N., Huaynoca, S., et al. (2017). Looking Back and Moving Forward: Can We Accelerate Progress on Adolescent Pregnancy in the Americas. Reprod. Health. 14, 83. doi:10.1186/ s12978-017-0345-y

Caro, D., Shueller, J., Ramsey, M., and Voet, W. (2009). Manual for Integrating Gender into Reproductive Health and HIV Programs: From Commitment to Action. 2nd ed. Washington, DC: US Agency for International Development. Population Reference Bureau.

Chanzanagh, H. E., Esmaeelzadeh, Z., and Zarsazkar, M. (2011). Gender in School Subject: A Case-Study on Iran's Primary Levels - School Subjects. Proced. - Soc. Behav. Sci. 15, 1832-1838. doi:10.1016/j.sbspro.2011.04.011

CIHR (2012). What a Difference Sex and Gender Make: A Gender, Sex and Health Research Casebook. Vancouver, British Columbia: Canadian Institutes of Health Reseach.

Creswell, J. W. (2012). Educational Research: Planning, Conducting, and Evaluating Quantitative and Qualitative Research. Boston: Pearson.

Damschroder, L. J., Aron, D. C., Keith, R. E., Kirsh, S. R., Alexander, J. A., and Lowery, J. C. (2009). Fostering Implementation of Health Services Research Findings into Practice: A Consolidated Framework for Advancing Implementation Science. Implement. Sci. 4, 50. doi:10.1186/1748-5908-4-50

Demaria, L. M., Galárraga, O., Campero, L., and Walker, D. M. (2009). Sex Education and HIV Prevention: an Evaluation in Latin America and the Caribbean. Rev. Panam. Salud Publica. 26, 485-493. doi:10.1590/s102049892009001200003

Denis, J. L., Hébert, Y., Langley, A., Lozeau, D., and Trottier, L. H. (2002). Explaining Diffusion Patterns for Complex Health Care Innovations. Health Care Manage. Rev. 27, 60-73. doi:10.1097/00004010-200207000-00007

Department of Education of the Municipality of Santiago (2018). Programa Comunal de Educación y Salud Sexual: Dirigido a Establecimientos de la Municipalidad de Santiago. Santiago: Department of Education of the Municipality of Santiago.

Derzon, J. H., Sale, E., Springer, J. F., and Brounstein, P. (2005). Estimating Intervention Effectiveness: Synthetic Projection of Field Evaluation Results. J. Prim. Prev. 26, 321-343. doi:10.1007/s10935-005-5391-5

DiStefano, C., and Kamphaus, R. W. (2006). Investigating Subtypes of Child Development. Educ. Psychol. Meas. 66, 778-794. doi:10.1177/0013164405284033

Domínguez Lara, S. (2012). Propuesta para el cálculo del Alfa Ordinal y Theta de Armor. Rev. Investig. Psicol. 15, 213-217. doi:10.15381/rinvp.v15i1.3684

DuPaul, G. J. (2009). Assessing Integrity of Intervention Implementation: Critical Factors and Future Directions. Sch. Ment. Health. 1, 154-157. doi:10.1007/ s12310-009-9016-7

Durlak, J. A., and DuPre, E. P. (2008). Implementation Matters: A Review of Research on the Influence of Implementation on Program Outcomes and the Factors Affecting Implementation. Am. J. Community Psychol. 41, 327-350. doi:10.1007/s10464-008-9165-0

Durlak, J. A. Y., and Weissberg, R. P. (2005). "A Major Meta-Analysis of Positive Youth Development Programs," in Meeting of the American Psychological Association, Washington, DC Estados Unidos, 18-21 agosto.

Eccles, M. P., and Mittman, B. S. (2006). Welcome to Implementation Science. Implementation Sci. 1, 1. doi:10.1186/1748-5908-1-1

Ehrhart, M. G., Aarons, G. A., and Farahnak, L. R. (2014). Assessing the Organizational Context for EBP Implementation: The Development and Validity Testing of the Implementation Climate Scale (ICS). Implement. Sci. 9, 157. doi:10.1186/s13012-014-0157-1
Estrada, F., Atienzo, E. E., Cruz-Jiménez, L., and Campero, L. (2021). A Rapid Review of Interventions to Prevent First Pregnancy Among Adolescents and its Applicability to Latin America. J. Pediatr. Adolesc. Gynecol. (In Press), 34, 491-503. doi:10.1016/j.jpag.2021.01.022

Fixsen Naoom, S. F., Blase, K. A., Friedman, R. M., and Wallace, F. (2005). Implementation Research: A Synthesis of the Literature. Tampa: University of South Florida. Louis de la Parte Florida Mental Health Institute), The National Implementation Research Network.

Forman, S. G., Shapiro, E. S., Codding, R. S., Gonzales, J. E., Reddy, L. A., Rosenfield, S. A., et al. (2013). Implementation Science and School Psychology. Sch. Psychol. Q. 28, 77-100. doi:10.1037/spq0000019

Gendered innovations (2020). Gender. Gendered Innovations in Science, Health \& Medicine, Engineering, and Environment. Available at: https:// genderedinnovations.stanford.edu/terms/gender.html (Accessed July 23, 2020).

Gibbons, R. D., Rush, A. J., and Immekus, J. C. (2009). On the Psychometric Validity of the Domains of the PDSQ: An Illustration of the Bi-factor Item Response Theory Model. J. Psychiatr. Res. 43, 401-410. doi:10.1016/ j.jpsychires.2008.04.013

Glasgow, R. E., Vogt, T. M., and Boles, S. M. (1999). Evaluating the Public Health Impact of Health Promotion Interventions: The RE-AIM Framework. Am. J. Public Health. 89, 1322-1327. doi:10.2105/ajph.89.9.1322

Greaves, L. (2012). "Why Put Sex and Gender into Health Research," in Designing and Conducting Gender, Sex, and Health Research. Editors J. Oliffe and L. Greaves (Thousand Oaks, CA: SAGE), 3-14.

Greenhalgh, T., Robert, G., Macfarlane, F., Bate, P., and Kyriakidou, O. (2004). Diffusion of Innovations in Service Organizations: Systematic Review and Recommendations. Milbank Q. 82, 581-629. doi:10.1111/j.0887378X.2004.00325.x

Haberland, N. A. (2015). The Case for Addressing Gender and Power in Sexuality and Hiv Education: A Comprehensive Review of Evaluation Studies. Int. Perspect. Sex. Reprod. Health. 41 (1), 31-42. doi:10.1363/4103115

Hahn, E. E., Munoz-Plaza, C. E., Schottinger, J. E., Brasfield, F. M., Gould, M. K., and Parry, C. (2019). Developing Innovative Models of Care for Cancer Survivors: Use of Implementation Science to Guide Evaluation of Appropriateness and Feasibility. Support. Care Cancer 27, 1737-1745. doi:10.1007/s00520-018-4425-5

Hair, J. F., Anderson, R. E., Tatham, R. L., Black, W. C., and Cano, D. (1999). Análisis Multivariante. 5th ed. Englewood Cliffs: Prentice-Hall.

Heidari, S., Babor, T. F., De Castro, P., Tort, S., and Curno, M. (2016). Sex and Gender Equity in Research: Rationale for the SAGER Guidelines and Recommended Use. Res. Integr. Peer Rev. 1, 2. doi:10.1186/s41073-0160007-6

Johnson, J. L., Greaves, L., and Repta, R. (2009). Better Science with Sex and Gender: Facilitating the Use of a Sex and Gender-Based Analysis in Health Research. Int. J. Equity Health. 8, 14. doi:10.1186/1475-9276-8-14

Johnson, J. L., Repta, R., and Kalyan, S. (2012). "Implications of Sex and Gender for Health Research: From Concepts to Study Design," in Designing and Conducting Gender, Sex, \& Health Research. Editors J. L. Oliffe and L. Greaves (Thousand Oak, California: SAGE Publications, Inc), 39-64. doi:10.4135/9781452230610.n3

Keogh, S. C., Stillman, M., Leong, E., Awusabo-Asare, K., Sidze, E., Monzón, A. S., et al. (2020). Measuring the Quality of Sexuality Education Implementation at the School Level in Low- and Middle-Income Countries. Sex Educ. 20, 119-137. doi:10.1080/14681811.2019.1625762

Kirby, D. (2001). Emerging Answers 2007: Research Findings on Programs to Reduce Teen Pregnancy and Sexually Transmitted Diseases. Washington, DC): National Campaign to Prevent Teen and Unplanned Pregnancy, 348-355. doi:10.1080/ 19325037.2001.10603497

Kirk, M. A., Kelley, C., Yankey, N., Birken, S. A., Abadie, B., and Damschroder, L. (2015). A Systematic Review of the Use of the Consolidated Framework for Implementation Research. Implement Sci. 11 (1), 72. doi:10.1186/s13012-016$0437-\mathrm{z}$

Klein, K. J., and Knight, A. P. (2005). Innovation Implementation. Curr. Dir. Psychol. Sci. 14, 243-246. doi:10.1111/j.0963-7214.2005.00373.x

Klein, K. J., and Sorra, J. S. (1996). The Challenge of Innovation Implementation. Acad. Manag. Rev. 21 (4), 1055. doi:10.2307/259164

Kululanga, L. I., Sundby, J., Malata, A., and Chirwa, E. (2011). Striving to Promote Male Involvement in Maternal Health Care in Rural and Urban Settings in 
Malawi - a Qualitative Study. Reprod. Health. 8, 36. doi:10.1186/1742-47558-36

Langford, R., Bonell, C. P., Jones, H. E., Pouliou, T., Murphy, S. M., Waters, E., et al. (2014). The WHO Health Promoting School Framework for Improving the Health and Well-Being of Students and Their Academic Achievement. Cochrane Database Syst. Rev. 32, CD008958. doi:10.1002/ 14651858.CD008958.pub2

Langley, A. K., Nadeem, E., Kataoka, S. H., Stein, B. D., and Jaycox, L. H. (2010). Evidence-based Mental Health Programs in Schools: Barriers and Facilitators of Successful Implementation. Sch. Ment Health. 2, 105-113. doi:10.1007/s12310010-9038-1

Lara, L. A. S., and Abdo, C. H. N. (2016). Age at Time of Initial Sexual intercourse and Health of Adolescent Girls. J. Pediatr. Adolesc. Gynecol. 29, 417-423. doi:10.1016/j.jpag.2015.11.012

Lau, R., Stevenson, F., Ong, B. N., Dziedzic, K., Treweek, S., Eldridge, S., et al. (2016). Achieving Change in Primary Care-Ccauses of the Evidence to Practice gap: Systematic Reviews of Reviews. Implement. Sci. 11, 40. doi:10.1186/s13012016-0396-4

Leiva, L., George, M., Antivilo, A., Squicciarini, A. M., Simonsohn, A., Vargas, B., et al. (2015a). Salud mental escolar: Logros de una intervención preventiva en salud mental en niños y niñas del primer ciclo de enseñanza básica. Psicoperspectivas 14, 31-41. doi:10.5027/psicoperspectivas-Vol14-Issue1fulltext-508

Leiva, L., George, M., Squicciarini, A. M., Simonsohn, A., and Guzmán, J. (2015b). Intervención preventiva de salud mental escolar en adolescentes: desafíos para un programa público en comunidades educativas. Univ. Psychol. 14, 1285-1298. doi:10.11144/Javeriana.upsy14-4.ipsm

Liang, S., Kegler, M. C., Cotter, M., Phillips, E., Beasley, D., Hermstad, A., et al. (2015). Erratum to: 'Integrating Evidence-Based Practices for Increasing Cancer Screenings in Safety Net Health Systems: a Multiple Case Study Using the Consolidated Framework for Implementation Research'. Implement. Sci. 11, 130. doi:10.1186/s13012-016-0477-410.1186/s13012-016-0494-3

Locke, J., Beidas, R. S., Marcus, S., Stahmer, A., Aarons, G. A., Lyon, A. R., et al. (2016). A Mixed Methods Study of Individual and Organizational Factors that Affect Implementation of Interventions for Children with Autism in Public Schools. Implement. Sci. 11, 135. doi:10.1186/s13012-016-0501-8

López, F., Carcedo, R. J., Fernández Rouco, N., and Caballero, M.-C. (2017). Afectos y conductas sexuales en adolescentes: diferencias y semejanzas en dos culturas, España y Colombia. Univ. Psychol. 16, 1. doi:10.11144/ Javeriana.upsy16-4.acsa

Lyon, A. R., and Bruns, E. J. (2019). From Evidence to Impact: Joining Our Best School Mental Health Practices with Our Best Implementation Strategies. Sch. Ment Health. 11, 106-114. doi:10.1007/s12310-018-09306-w

Lyon, A. R., Cook, C. R., Brown, E. C., Locke, J., Davis, C., Ehrhart, M., et al. (2018). Assessing Organizational Implementation Context in the Education Sector: Confirmatory Factor Analysis of Measures of Implementation Leadership, Climate, and Citizenship. Implement. Sci. 13, 5. doi:10.1186/s13012-0170705-6

Macintyre, A. K., Montero Vega, A. R., and Sagbakken, M. (2015). From Disease to Desire, Pleasure to the Pill: A Qualitative Study of Adolescent Learning about Sexual Health and Sexuality in Chile. BMC Public Health. 15, 945. doi:10.1186/ s12889-015-2253-9

Maritim, P., Zulu, J. M., Jacobs, C., Chola, M., Chongwe, G., Zyambo, J., et al. (2019). Factors Shaping the Implementation of the SAFE Strategy for Trachoma Using the Consolidated Framework for Implementation Research: A Systematic Review. Glob. Health Action. 12, 1570646. doi:10.1080/16549716.2019.1570646

Measor, L. (1996). Gender and Sex Education: A Study of Adolescent Responses. Gend. Educ. 8 (3), 275-288. doi:10.1080/09540259621520

Meyers, D. C., Katz, J., Chien, V., Wandersman, A., Scaccia, J. P., and Wright, A. (2012). Practical Implementation Science: Developing and Piloting the Quality Implementation Tool. Am. J. Community Psychol. 50, 481-496. doi:10.1007/ s10464-012-9521-y

Montero V, A. (2011). Educación sexual: un pilar fundamental en la sexualidad de la adolescencia. Rev. Méd. Chile. 139, 1249-1252. doi:10.4067/S003498872011001000001

Morgan, R., George, A., Ssali, S., Hawkins, K., Molyneux, S., and Theobald, S. (2016). How to Do (Or Not to Do) Gender Analysis in Health Systems Research
Gender Analysis in Health Systems Research. Health Policy Plan 31, 1069-1078. doi:10.1093/heapol/czw037

Neuman, W. L. (2013). Social Research Methods: Qualitative and Quantitative Approaches. Edinburgh Gate: Pearson Education Limited.

Ninsiima, A. B., Coene, G., Michielsen, K., Najjuka, S., Kemigisha, E., Ruzaaza, G. N., et al. (2019). Institutional and Contextual Obstacles to Sexuality Education Policy Implementation in Uganda. Sex Educ. 20, 17-32. doi:10.1080/ 14681811.2019.1609437

Obach, A., Sadler, M., Aguayo, F., and Bernales, M. (2018). Salud sexual y reproductiva de hombres jóvenes en Chile: resultados de un estudio cualitativo. Rev. Panam Salud Publica 42, 1-7. doi:10.26633/ RPSP.2018.124

Obach King, A., Sadler, M., and Jofré, N. (2017). Salud sexual y reproductiva de adolescentes en Chile: el rol de la educación sexual. Rev. Salud Pública 19, 848-854. doi:10.15446/rsap.v19n6.70023

Olson, B. H., Sigman-Grant, M., and Braun, M. T. (2020). Workplace Lactation Support: Using Implementation Climate to Inform a New Model. Breastfeed. Med. 15, 417-422. doi:10.1089/bfm.2020.0037

Panchaud, C., Keogh, S. C., Stillman, M., Awusabo-Asare, K., Motta, A., Sidze, E., et al. (2018). Towards Comprehensive Sexuality Education: a Comparative Analysis of the Policy Environment Surrounding School-Based Sexuality Education in Ghana, Peru, Kenya and Guatemala. Sex Educ. 19 (3), 277-296. doi:10.1080/14681811.2018.1533460

Pastor, D. (2010). Cluster Analysis in the Reviewer's Guide to Quantitative Methods. Editors G. R. Hancock and R. O. Mueller (New York, NY: Routledge), 41-54.

Patrick, C. J., Hicks, B. M., Nichol, P. E., and Krueger, R. F. (2007). A Bifactor Approach to Modeling the Structure of the Psychopathy Checklist-Revised. J. Pers. Disord. 21, 118-141. doi:10.1521/pedi.2007.21.2.118

Pawson, R. (2013). The Science of Evaluation. A Realist Manifesto. London: SAGE Publications.

Prieto, G., and Delgado, A. R. (2010). Fiabilidad Y Validez. Pap. Psicol. 31, 67-74.

Proctor, E. K., Landsverk, J., Aarons, G., Chambers, D., Glisson, C., and Mittman, B. (2009). Implementation Research in Mental Health Services: An Emerging Science with Conceptual, Methodological, and Training Challenges. Adm. Pol. Ment Health. 36, 24-34. doi:10.1007/s10488-008-0197-4

Rocha, A. C., Duarte, C., and Duarte, C. (2016). Factors Facilitating Implementation of School-Based Sexuality Education in Portugal. Eur. J. Contracept. Reprod. Health Care 21, 30-38. doi:10.3109/ 13625187.2015.1057809

Rotheram-Borus, M. J., Swendeman, D., Flannery, D., Rice, E., Adamson, D. M., and Ingram, B. (2008). Common Factors in Effective HIV Prevention Programs. AIDS Behav. 13 (3), 399-408. doi:10.1007/s10461-008-9464-3

Sadler, M., Obach, A., and Biggs, A. (2010). Estudio Barreras de acceso a los servicios de salud para la prevención del embarazo adolescente en Chile. Fundación CulturaSalud y Programa Nacional de Salud Integral de Adolescentes y Jóvenes del Ministerio de Salud Gobierno de Chile. doi:10.13140/RG.2.1.3968.6889

Sheldrick, R. C., Henson, B. S., Merchant, S., Neger, E. N., Murphy, J. M., and Perrin, E. C. (2012). The Preschool Pediatric Symptom Checklist (PPSC): Development and Initial Validation of a New Social/emotional Screening Instrument. Acad. Pediatr. 12, 456-467. doi:10.1016/j.acap.2012.06.008

Shuman, C. J., Powers, K., Banaszak-Holl, J., and Titler, M. G. (2019). Unit Leadership and Climates for Evidence-Based Practice Implementation in Acute Care: A Cross-Sectional Descriptive Study. J. Nurs. Scholarsh. 51, 114-124. doi:10.1111/jnu.12452

Silva, M. M., and Leiva, L. (2014). Opiniones profesionales de la salud sobre el embarazo en la adolescencia. Psicoperspectivas 13, 82-92. doi:10.5027/ psicoperspectivas-Vol13-Issue3-fulltext-410

Sung, N. S., Crowley, W. F., Genel, M., Salber, P., Sandy, L., Sherwood, L. M., et al. (2003). Central Challenges Facing the National Clinical Research enterprise. JAMA 289, 1278-1287. doi:10.1001/jama.289.10.1278

Tannenbaum, C., Greaves, L., and Graham, I. D. (2016). Why Sex and Gender Matter in Implementation Research. BMC Med. Res. Methodol. 16, 145. doi:10.1186/s12874-016-0247-7

Tarkang, E. E. (2014). Perceived Family Support Regarding Condom Use and Condom Use Among Secondary School Female Students in Limbe Urban 
City of Cameroon. BMC Public Health. 14, 173. doi:10.1186/1471-245814-173

Turner, K., Trogdon, J. G., Weinberger, M., Stover, A. M., Ferreri, S., Farley, J. F., et al. (2018). Testing the Organizational Theory of Innovation Implementation Effectiveness in a Community Pharmacy Medication Management Program: A Hurdle Regression Analysis. Implement. Sci. 13, 105. doi:10.1186/s13012-0180799-5

UNESCO (2018). International Technical Guidance on Sexuality Education. Paris: United Nations Educational Scientific and Cultural Organization SDGs. doi:10.1523/JNEUROSCI.0529-04.2004

Varsi, C., Ekstedt, M., Gammon, D., and Ruland, C. M. (2015). Using the Consolidated Framework for Implementation Research to Identify Barriers and Facilitators for the Implementation of an Internet-Based Patient-Provider Communication Service in Five Settings: A Qualitative Study. J. Med. Internet Res. 17, e262. doi:10.2196/jmir.5091

Wandersman, A., Duffy, J., Flaspohler, P., Noonan, R., Lubell, K., Stillman, L., et al. (2008). Bridging the gap between Prevention Research and Practice: The Interactive Systems Framework for Dissemination and Implementation. Am. J. Community Psychol. 41, 171-181. doi:10.1007/ s10464-008-9174-z

Wang, B., Stanton, B., Deveaux, L., Poitier, M., Lunn, S., Koci, V., et al. (2015). Factors Influencing Implementation Dose and Fidelity Thereof and Related Student Outcomes of an Evidence-Based National HIV Prevention Program. Implement. Sci. 10 (1), 44. doi:10.1186/s13012-015-0236-y

Weiner, B. J. (2009). A Theory of Organizational Readiness for Change. Implement. Sci. 4, 67. doi:10.1186/1748-5908-4-67
Weiner, B. J., Belden, C. M., Bergmire, D. M., and Johnston, M. (2011). The Meaning and Measurement of Implementation Climate. Implement. Sci. 6, 78. doi:10.1186/1748-5908-6-78

Weist, M. D., Lever, N. A., Bradshaw, C. P., and Owens, J. S. (2014). "Further Advancing the Field of School Mental Health," in Further Advancing the Field of School Mental Health in Handbook of School Mental Health. Research, Training, Practice and Police. Editors J. Weist, M. D. Lever, N. Bradshaw, and C. P. Sarno (New York, NY: Springer), 1-14. doi:10.1007/978-1-4614-7624-5_1

Conflict of Interest: The authors declare that the research was conducted in the absence of any commercial or financial relationships that could be construed as a potential conflict of interest.

Publisher's Note: All claims expressed in this article are solely those of the authors and do not necessarily represent those of their affiliated organizations, or those of the publisher, the editors, and the reviewers. Any product that may be evaluated in this article, or claim that may be made by its manufacturer, is not guaranteed or endorsed by the publisher.

Copyright $\odot 2021$ Torres-Cortés, Leiva, Antivilo-Bruna and Zavala-Villalón. This is an open-access article distributed under the terms of the Creative Commons Attribution License (CC BY). The use, distribution or reproduction in other forums is permitted, provided the original author(s) and the copyright owner(s) are credited and that the original publication in this journal is cited, in accordance with accepted academic practice. No use, distribution or reproduction is permitted which does not comply with these terms. 